\title{
Patients' light preferences in hospital wards: related to light atmosphere in Danish homes
}

\author{
L. Stidsen ${ }^{1}$, H. S. Bjerrum ${ }^{1}$, P. H. Kirkegaard ${ }^{1}$, N. Thuesen ${ }^{2}$ \\ \& A. M. Fisker ${ }^{2}$ \\ ${ }^{I}$ Department of Civil Engineering, Aalborg University, Denmark \\ ${ }^{2}$ Department of Architecture, Design and Media Technology, \\ Aalborg University, Denmark
}

\begin{abstract}
When designing Danish hospitals in the future, patients, staff and guests are in focus and it is especially important to design an environment with knowledge of users sensory and functionally needs. Likewise, focus should be on how hospital wards can support patients' experiences or maybe even how it can have a positive influence on the recovery process. The present paper introduces the human perspective and the Danish cultural approach in illuminating homes and how it can contribute to innovative lighting design at hospitals. The importance of having a holistic approach to lighting design is introduced based on the theory by Gernot Böhmes i.e. "concept of atmosphere" dealing with the effect of experiencing atmosphere. The aim of this study for design of a lighting concept for wards is to get qualified information on patients light preferences for light atmosphere by studying the everyday use of light in homes.

This explorative study displays the preferred light atmosphere in Danish homes in the age group of 60-85 years old people. With an anthropologically approach to the subject using semi structured interviews, the goal is to explore preferences for light atmosphere when the user are in the control of the light and get inspiration on how they create a private sphere. The purpose is also through this analyse to display cultural trends of illuminating homes, therefore, the paper will introduce the design lighting concept for wards based on different everyday situation activities from a hospital ward.
\end{abstract}

Keywords: lighting design, hospital ward, light atmosphere, private sphere, cultural factors, patients light preferences, lighting Danish homes. 


\section{Introduction}

Design parameters for creating a pleasurable light atmosphere in hospital wards are a complex field to study. Researchers have investigated the topic and display some of the important factors in Evidence Based Design (Ulrich and Zimring [1]), Healing Architecture (Frandsen et al. [2] and Dalke et al. [3]) elaborated on the field by studying the importance of colour and light in hospital design. The users of hospital wards are diverse and they have all special needs and preferences for light depending on their activity and purpose of using the ward.

Foqué et al. [4] point out that light is an important factor in experiencing ward atmosphere. The philosopher Böhme [5] presents the concept of atmosphere and highlights the bodily presence in the evaluation of atmosphere as important. Madsen [6] studies the effect of light zones, Millet [7] claims that light reveals architecture and Malnar and Vodvarka [8] present light as one of the important factors in sensory design. All in all, the environmental factors, the ward atmosphere, and light must support the staff's working conditions, the patient's private atmosphere and the visitors' experiences of being guests (Jörgensen et al. [9], Knez and Enmarker [10], Mc Clughan et al. [11], Stidsen et al. [12]).

Studying theoretical instructions for lighting design (Leslie and Conway [13], Loe and Rowlands [14], Cuttle [15], Bean [16]) it is interesting to study how the light is integrated in an architectural context. A practical study of e.g. Frank Lloyd Wright (Heinz [17]) presents a holistic approach to architectural experiences including lighting design. But there seem to be a gap between the theoretical information of Gernot Böhmes and best practice of lighting design, which does not account for the cultural differences as well as the geographical difference preferences of artificial light. The cultural issue is important for the experience of a space and our hypothesis is that artificial light is used by the way we experiencing daylight (Bille and Sørensen [18], Stidsen et al. [19]).

These diverse needs and preferences require different light scenarios at the ward and it seems to be incompatible issues regarding lighting design. By rethinking ward lighting and by creating activity based light scenarios, the different user of the ward should be able to achieve a pleasurable light atmosphere. In the process of rethinking lighting design for hospital wards, parallel studies have been made. These studies display lighting problems of existing wards and are collecting inspiration from comparative places to the ward.

The aim of this study is to collect information of light preferences and light atmosphere in private settings and to clarify how light is used in Danish homes and use it as inspiration to lighting design for patient zones in hospital wards. Therefore, this paper presents a Danish approach to illuminate our private sphere and display some of the cultural issues important for using artificial light in a Danish design context. Lastly, we present a proposal for how the gained information can be translated to a lighting concept for hospital wards. 


\section{Methods}

Present Evidence Based Design is an important agenda and in addition Malkin et al. [20] has produced a visual guide of the important design issues presented in an American hospital context. The research through design and the knowledge of design professionalism can contribute to the existing knowledge with innovation because the designers have the ability to turn everything upside down and rethink, refine and combine existing knowledge in new innovative ways.

To find interesting results in a Danish design context and to explore new approaches in lighting design in hospital wards, we prefer using qualitative methods rather than more scientific approaches. Seeberg [21] describes the difference in the subject field to distinguish between the stable versus the reflexive object. Regarding the reflective objects, it is appropriate to use methods where the understanding of the contextual and constructed is embedded in the method. Qualitative methods are thus particularly suited for scientific studies dealing with strength and depth in exploring new ways of looking at themes. In this context, anthropological methods are particularly interesting with the emic approach to the study. As Hastrup [22] writes: "The empirical claim implies that anthropology deals with (specific, known and named) people's actions and the perception of their own lives and activities (...)".

The approach of using Anthropological methods focuses on the informant's own world and experience. Therefore, the method is interesting in connection to user-centred design. Here is the opportunity to examine the user group's preferences for light, their way of illuminate in their private sphere.

\subsection{Framework for the interview guide}

To establish the framework of the interview and to form a usable interview guide, we studied different approaches in experiencing wards and the daily life at a hospital. Beyond the theoretical and practical design studies, we interviewed 2 nurses at Odense University Hospital, Department of Orthopedically surgery (hereafter O3) to clarify their needs for light and their understanding of patient comfort.

Inspired by Bohme's ideas of bodily presence in experiencing atmosphere and in order to understand the patient's experience of a hospitalization, we were allowed to observe the daily rhythm at the ward seen from the bedside for one day and night. That way we were having a bodily experience of the situation of being hospitalized. The purpose was to collect information gained through intersubjective discussions and studies of everyday situations for patients. This is not to say that we have the knowledge of what it is like being a patient and what patients' needs are, but the study contributes with important and interesting issues, which are specified in the interviews guide.

Through this study, we also found some critical issues about the existing illumination of the ward and got new ideas of improvements. To clarify the staffs' needs and preferences for light, Thuesen [23] studied the workflow at the ward and the effect of zoning the ward in staff area, patient area and visitor area. 
By interviewing and observing the staff and having a personal experience of everyday activities at a hospital ward, we made the framework of the interview. Through the interview process, the informants added important viewpoints to the categories and they refined and elaborated concepts as "Dining", "Watching TV", "Going to bed", "Sedentary Activities" as reading, knitting, sewing, solving crossword, "Upstanding Activities" as walking, playing music instruments, cooking, etc. and at last "Communication/social interaction" as having guests, having conversations with staff etc.

\subsection{Semi structured interviews}

The typical method for an anthropological study is to conduct fieldwork and participant observation combined with formal and informal interviews. The observation of participants has primarily the object as common area, and in this study we have chosen the theme of lighting. Simultaneously, the group we want to study (patients and potential patients) is not a naturally cohesive group. "The community" is formed on a common experience through the admission; however, it is short and usually crucial for the patient's identity. Hence, we have chosen semi-structured interviews as the main method for this study. A method that is ideal for what Rubow [24] calls "multi-site field work"

It is a challenge to work in a multi-sited field as the informants' homes. Many people have trouble describing their own perception of light; maybe it is because light is primarily phenomenon that we relate intuitively and experientially to. Therefore, we have combined our interviews with a visual approach to fieldwork using photo albums Winther [25]. Both album and interview guide focuses on keeping the interview concretely and descriptively. As Kvale [26] writes: The interview itself should be the main issues of descriptive character "What happened and how did it happen? How did you feel then? What was your experience?"

\subsection{Photo documentation}

The specificity of this study is verbalizing something that very few have articulated. There is a tendency to see illumination in our daily life as something that relates to an instinctive non-reflective level. As Böhme claims, we just note whether we like being in a space, or if it is "nice", "cosy" or "safe", but we rarely get to behave in a more conscious way.

The generation of knowledge in qualitative methodology is an interaction between informant and researcher. This means that there may be a bias in interactions when the researcher appears as an expert in the area that the informant has previously reflected upon tacitly rather than explicitly. In such a case, the researcher may have a disproportionately large influence on the informant's statements. To minimize this effect, we have chosen to let the informants start working alone by giving them a disposable camera and a few instructions. We wanted to get as close a description of their everyday use of light as possible. Therefore, the method was given the following form: Firstly, the informants took pictures of their use of light in everyday life. Then we 
developed pictures and made a photo album. Afterwards we interviewed informants in their homes and used the photo album as structure for the interview. Lastly, we transcripted and analysed the interview.

Deductively we asked specifically into selected categories during the interview. The categories were chosen over known activities taking place at a hospital, but as reflected in every situation in homes. The categories were as follows: "Dining", "Watch TV", "Go to bed", "Sedentary Activities" as reading, knitting, sewing, solving crossword mm, "Upstanding Activities" as walking, playing music instruments, cooking, etc., and the last category were "Communication/social interaction" as having guests etc.

To optimize the method of the study, we undertook a pilot study. This was primarily to ensure that the participant's tasks of working alone were easy to understand and to test the idea of structuring the interview over albums. We wanted to be sure of the participant's feeling on top of the interview and experts of their way of using light.

\subsection{Selection of informants}

Basically the goal was to select informants among patients at $\mathrm{O} 3$. By choosing informants from the department, we wanted to interview the patients at home before the admission and later during hospitalization. We wanted to achieve a random selection of informants, the possibility of having a re-interview and be able to get informants themselves to match their daily use of light with their experiences of ward lighting. Therefore, we started out trying to recruit participants at the Joint Care meetings at $\mathrm{O} 3$ two to three weeks before the operation. Here the nurses helped us distributing project information and the coming patients were supposed to convene the project. This method did not succeed. Maybe because patients had too many concerns about the coming operation or maybe it was too scary to share pictures of the private sphere with strangers.

Consequently, we changed the recruitment approach and found it comparable to find participants from a reference group similar to the group of patients at the hospital. We distributed a mail with project information to 44 persons in our network and asked them being ambassadors for the project and help us finding informant in the age group of 60-85 years old. This method succeeded and we got 12 informants, 8 couples and 4 singles in the age of 61-86 years old. Geographically located in five different cities in Jutland, Denmark both from the countryside and from the centre of the main capital of Jutland.

Now the method using proposed re-interview was not applicable for this study. Patient relation to ward lighting was no longer a central question in the interview, but some informants told voluntarily about experiences from hospitals. It was often related to questions about good or bad experiences of light outside the home, or in their questions to the goal of the study. This information is included in this study.

Data were collected during the period ultimo November 2010 to beginning of January 2011. That time of the year where the Danes have a lighting tradition using candle lights and having Christmas décor in their homes. This season is not 
representative for our light preferences through the year, but the seasonally changes in using light is mentioned in all interviews. The group of informants ranging from those who have a special interest in light and have chosen their house because of its location and daylight distribution, to informants who have not noticed the light as important for their living.

\subsection{Field work and validity}

Wadel [27] claims that Fieldwork as participation observation entails at least three types of challenges and skills the field worker must possess. Firstly, the ability to obtain access to the participators observations and the other skill is to be able to possess a repertoire of roles in the progress of fieldwork. Thirdly, it is important to be "a sociologist on oneself". In this way, Wadel initiates his reflections on the anthropologist's task of fieldwork in own culture. The field worker's challenge is to find a role that can provide access to a field. The role must simultaneously make it possible to collect data, where communication can take place in culturally accepted and understandable terms. The researcher should not insist on just being a scientist.

Caused temporal and access reasons in the study, we chose not to work with prolonged participant observation. However, this dilemma was considered. In connection with the recruitment of informers, it was important that they understood in which context the data would be used. Therefore, the participants have been aware that it is a research project and the interviewer's role as a researcher. The generation we are working with in this study is typically informants with a lot of respect for authority and knowledge holders. Wadel suggests that it could be beneficial for the field worker to take the role as apprentice or trainee because it is a known role in many contexts. In this study, it has not been possible for us to establish such a relationship in the interview situation. Instead we have, as described, sought to minimize the influence on the informants' first reflections of illumination through photo documentation.

Simultaneously, it was important for us to be "a sociologist on oneself" in the interview situation where the interviewer was often met with great respect. Informants were concerned about whether they had taken the right pictures, whether they were good enough and whether they knew anything about lighting. Because the interviewer also possessed "the researcher role", we spent time before the interview appreciating the informant's work and worked on a more equal relationship in the interview. It was an advantage for the interview situation that it took place in informants' homes. This meant that the interviewer simultaneously got the role as a guest and it gave the hosts the possibility to define rules for interaction.

One of the major advantages of photo-documentation method was that the photo album created a natural and familiar situation. An interview may sound unfamiliar and promoted as something of "experts". To show visitors pictures is another matter. It is a familiar situation, making it easier for informants to relax in the interaction. At the same time the pictures helped to keep the interview practical and user-oriented. In that way we prevented the problem that Bernard [28] describes as finding good informants who are experts on the questions. He 
claims that an important question for ethnography is the following: "Are a few informants really capable of providing adequate information about a culture?" And his answer is that it depends on two things: choosing good informants and asking them things they know about.

When informants were sitting with their own pictures in their own house, it was obvious that they were experts in their own lives and they felt able to talk about the illumination. The disadvantage of this method was that it might have contributed to filter out some informants because the user group may have felt it prohibitively and confusing even to take pictures. In 4 cases, the informants agreed to participate but they needed help to take the pictures. Through the process, the informers chose to be interview individual or together with their partner.

A great advantage of the anthropological methods using fieldwork is that the participant observation complements the conversations and interviews. It is a socalled method triangulation (Selmer [29]). In other words, the study illustrates both the informants' conceptions of themselves and their practices. Not using prolonged participant observation, the approach using photo albums as interview guide and visiting the participant's homes has the function of method triangulation. The fact that the interview took place in the home gave the interviewer the opportunity to compare the pictures with the reality and have an experience about the type of environment for the illumination.

\section{Analyse: light preferences in Danish homes}

The collected data were transcribed in real time method, where the transcripter writes along the tape that is running nonstop. The data was sorted by the previously mentioned categories and analysed. Information included in this analysis is, as well as the earlier presented studies, background for a proposal of lighting concept in hospital wards. The gained knowledge of collected information is going to be translated to a concept for lighting hospital wards.

\subsection{Dining}

The activity of having dinner can be divided into two different situations. The every day dinner at home for residents was eaten in the kitchen or maybe in the same form in the dining room. At weekends, the dinner experience should be different, so if they had a dining room or a living room with a dining table the meal was served there. Almost all informants, across aesthetic choices of interior design and placement of dining table, chose an illumination where a pendant would be hanging down over the table creating a light zone containing table and chairs. The pendant hanging over the table was often flexible and could be moved up or down and from side to side. Another situation was if they had guests for dinner. Then the informants turn on more light in the room. Many illuminated the table with candlelight or maybe a dimmed light in the pendant. To compliment the desired atmosphere, most of the informants preferred having a light zone at the other end of the room emphasizing the character of the room. 


\subsection{Watching TV}

When it comes to the activity of watching TV, the light atmosphere was very important. The most important thing to avoid in the illumination was light reflections on the TV screen. Therefore, most of the luminaires were located beside or behind the TV or somewhere away from the observer location.

\subsection{Going to bed}

In general, the lighting design of bedrooms was not a focus area for the informants. Many were apologizing for the illumination of this room; and it seemed to be illuminated by chance arranged with the "left over" luminaires. The analysis showed that the activity of "going to bed" or "having a rest" could be split into two different categories i.e. those who are reading lying in the bed and those who do not read in bed.

Most of the informants had a ceiling mounted luminaire placed centrally in their bedroom. The luminaires were usually "switched on" when entering the room, and then "switched off" as soon as possible when they had turned on the bedside lamps. The informants who read sitting or lying in the bed knew exactly how the light should be distributed from above the head and how to avoid conflicts between couples if only one was enjoying the reading from bedside.

In some cases, the informants had trouble seeing the contents of the closet and desired to have direct light placed there.

\subsection{Sedentary activities}

Analysing the sedentary activity as reading, knitting, sewing, solving crossword etc. produce several interesting answers of light preferences. The informants were focused on the subject and had a pronounced opinion about the light atmosphere for this activity. The usability of the lamps was important and many informants had floor lamps or lamps mounted to the wall right above and behind the chair or sofa to create the perfect light. Almost all informants were in this situation using a primary luminaire for visual task lighting and then secondary luminaires for light in the peripheral vision creating light atmosphere. Almost all of the participants were conscious about the fact that they need more light now than when they were young.

\subsection{Upstanding activities}

When it comes to upstanding activities such as walking in the hallway, using the bathroom or cooking, it seems to be important to have a general illumination supported by specific task lighting if necessary.

The general light preferences for standing activities were to have a uniform light distribution so every part of a room appears bright and an illumination coming from the ceiling supported with specific task lighting right where it is needed. For work related light, it seems to be important to see the space around you in a uniform way. If the space is used as a walking area as in a hallway or 
when entering the bedroom, the light should just distribute enough light to see where you are walking, and prevent accidents.

\subsection{Communication / social interaction (having guests, conversations)}

The situations where the informants are having social interactions as having guests in their home, they presented their homes in the best light. They turned on almost every luminaire in the "guest area" as a gesture of welcoming visitors. Almost every informant mentioned that they light more candles and that they illuminate their living room with many luminaires, so the room is filled with a warm light atmosphere and myriads of light zones. The luminaires were mostly located near the walls in varying heights often supplemented by luminaires highlighting the tables. All luminaires were placed so they emphasized the room appearance in different light settings. When the communication was in connection to work situation it was different. Then the informers preferred a more uniform light atmosphere. One informant, working in a workshop for capacity weak people, had a problem using pendants and having dark areas in a classroom because it could prevent contact with users. She preferred a light distribution with fluorescent light tubes. Here she felt a good connection with the workshop users, and pointed out that it was very necessary to have good light.

This analysis of the everyday use of light in Danish homes among people in the age group of 60-85 years old established a clear picture of this user group's preference for everyday illumination. The interviews contributed with new subjects important to the informants.

"Daylight" was important for almost everyone and they were generally conscious about location and orientation of the house in relation to the sun. Many mentioned also the importance of getting enough light at wintertime. The number of "Light zones" and luminaires in the room were also an issue in the illumination of their homes. We counted up to 14 luminaires in a living room and it was important that the light could be varied and flexible of use. The "Placement of luminaires" seemed to be near the walls illuminating the corners and creating a dark zone in the middle of the room. The consumption of "Candle lights" is enormous and it seemed to be synonymous with the Danish saying "hygge" (translated to "cosiness") in Danish homes. The informant had an impression of "hospitals environment" being cool and too white, and it was mentioned that at night the light was often disturbing the sleep. Many of the informants claimed that the illumination of southern Europe housing was unsympathetic and unpleasant. They were not able to find it comfortable or cosy to be in a light atmosphere using fluorescent light tube or light bulb mounted to the centre of the ceiling in a room where they were suppose to relax and feel at home. Lastly, they all had a favourite place in their living room. They had different ways of creating a private sphere around the place or ways of illuminating the area, but they all had there "own" place where they liked to relax.

The explorative study contributed with new approaches for the lighting design of hospital wards. As we experience lighting in hospital wards today, it seems to be a lighting concept having a uniform light distribution supplemented by a 
private illumination at bedside. The patient can control this private luminaire as well as it is used as specific task lighting by the staff. The uniform light distribution is suitable for general task lighting for the staff. This lighting concept is typically for illumination public area and there is a huge difference to familiar illumination of the private sphere. The Danish homes we generally prefer many luminaires, and a varied light distribution and intensity. The flexibility as well as the control of the light is important factors in feeling a pleasurable light atmosphere and the light is used as a gesture welcoming guests.

It is not possible to illuminate a ward with candlelight, but the opportunity illuminate a room in a flexible way placing luminaires around the ward seem to have a positive impact on experiencing a pleasurable light atmosphere for the different users. When it comes to creating the perfect light setting when reading or watching TV, the illumination and light atmosphere should please the patients comfort and prevent light reflections in the TV screen. Dividing the ward in user zones as well as vertical grid locates the luminaires near the walls. In a horizontal grid in three zones, "High", "middle" and "low" most of the luminaires are placed in the middle zone. The light distributions are modulated into the room through lampshades supplied with downlights/spots distributed to the place where it is needed. The luminaires can be divided into "primary luminaire" or "secondary luminaire". The purpose of the "Primary luminaires" is to distribute light for visual tasks as reading, solving crosswords, or as the pendant hanging over the table so we can se what we are eating. "Secondary luminaires" have the purpose of creating atmosphere. It can be small luminaires in the other part room illuminating in a way that it defines the architectural space; it can be candlelight's in the windows or shelf light etc.

\section{Conclusions}

As mentioned the purpose of this study collecting data from the private sphere is to get information and inspiration for the development of ward lighting for patients at Odense University Hospital, Department of orthopedically surgery (O3). The explorative study contributed with information on familiar light experiences and it innovate the process of creating a private sphere with pleasurable light atmosphere at the ward.

The information from the interviews supported our hypothesis of having a Danish light culture using several luminaires in our environment, and thus various light zones and different types of light distributions in our private sphere. With the aim of creating an innovative design and having the focus on designing a pleasurable light atmosphere in hospital wards, it seem to both useful and successful to study the every day use of light for diverse activities in private homes.

Therefore, we recommend a lighting design containing the possibility to change light according to user needs and user preferences focused on everyday activities at the ward. The concept of illuminating should contain several luminaires located around the ward and mostly near the walls in the vertical plan and in the middle zone of the horizontal plan. If the recommendations of light 
distribution are complied, the patients should have the opportunity to achieve a pleasant light atmosphere at the ward.

The lighting concept is going to be installed and tested at OUH department O3. The evaluation will be on the patient's needs and preferences for light and their experiences of light atmosphere. The concept of ward lighting and practically examples will be presented at the conference Light 2011.

\section{References}

[1] Ulrich, R. \& Zimring, C. The Role of the Physical Environment in the Hospital of the 21st Century: A Once-in-a-Lifetime Opportunity, The Center for Health Design, 2004

[2] Frandsen, A.K., Mullins, M., Ryhl, C., Folmer, M.B., Fich, L.B., Øien, T.B. \& Sørensen, N.L., Helende Arkitektur, 2009.

[3] Dalke, H., Littlefair, P.J. \& Loe, D.L., Lighting and colour for hospital design, TSO, England, 2004

[4] Foqué, R., Lammineur, M. \& Foqué-Denkens-Adriaenssens, A., "Designing for patients: a strategy for introducing human scale in hospital design”, Design Studies, vol. 16, pp. 29, 1995.

[5] Böhme, G., Atmosphere as the Fundamental Concept of a New Aesthetics, Sage, 1993

[6] Madsen,M, Lysrum -som begreb or redskab, Kunst akadamiets arkitektskole, p. 216, 2002

[7] Millet, M.S., Light Revealing Architecture, John Wiley \& Sons Inc, New Jersey, 1996.

[8] Malnar, J.M. \& Vodvarka, F., "The light fantastic" in Sensory Design University of Minnesota Press, Minnesota, pp. 199, 2004

[9] Jörgensen, K.N., Römma, V. \& Rundmo, T. “Associations between ward atmosphere, patient satisfaction and outcome.” Journal of Psychiatric and mental Health Nursing, vol. 16, pp. 113-120, 2009.

[10] Knez, I. \& Enmarker, I, Effects of Office Lighting on mood and Cognitive Performance And A Gender Effect on Work-Related Judgement, pp. 553,1998 .

[11] McClughan, C.L.B., Aspinall, P.A. \& Webb, R.S., "The impact of lighting on mood”, Lighting Research Technology, vol. 7, no. 31, pp. 88, 1999

[12] Stidsen, L., Kirkegaard, P.H. \& Fisker, A.M., "Design parameters for evaluating light settings and light atmosphere in hospital wards”, 2nd CIE Expert Symposium on Appearance, When Appearance meets Lighting, IbeBiv, Gent, pp. 136, 2010

[13] Leslie, R. \& Conway, K.M. 1996, The Lighting Pattern Book for Homes, McGraw-Hill, Rensselaer Polytechnic Institute, Troy, New York.

[14] Loe, D.L. \& Rowlands, E., "The art and science of lighting: A strategy for lighting design”, Lighting Research Technology, vol. 28, pp. 153-164. 1996.

[15] Cuttle, C., Lighting by design, second edn, Architectural Press, Oxford, UK. 2008 
222 Lighting in Engineering, Architecture and the Environment

[16] Bean, R., Lighting -interior and exterior, Architectural Press, Oxford, UK. 2004

[17] Heinz, T.A. 2000, Frank Lloyd Wright's Stained glass and lightscreens, Gibbs Smith, Layton, Utah.

[18] Bille, M. \& Sørensen, T.F., "Anthropology of Luminosity: The Agency of Light”, Journal of Material Culture, no. 12, pp. 263. 2007

[19] Stidsen, L., Kirkegaard, P.H. \& Fisker, A.M., "Design proposal for pleasurable light atmosphere in hospital wards”, Knemesi, Italy, pp. 366. 2010.

[20] Malkin, J. A., Visual reference for evidence-based design, Center for Health Design, Concord, CA. 2008.

[21] Seeberg, Jens: "Forsknings kvalitative fundament - om kvalitativ naturvidenskab og objektivt feltarbejde”, Tidsskrift for Forskning i Sygdom og Samfund. 2009.

[22] Hastrup, Kirsten: “Ind i verden. ” Hans Reitzels Forlag, 2010

[23] Thuesen, N. "Optimizing lighting design for hospital wards by defining user zones" Conference Light 2011,

[24] Rubow, Cecilie: Samtalen - interviewet som deltagerobservation, "Ind i verden", 2010

[25] Winther, I.W., Hjemlighed - Kulturfoenomenologiske studier, Danmarks Pædagogiske Universitet, København, 2006

[26] Kvale, Steinar: "An introduction to Qualitative Research Interviewing" Sage Publications, Inc. 1996

[27] Wadel, Cato: "Feltarbeid $i$ egen kultur”, Hegland Trykkeri A/S, Flekkefjord 1991

[28] Bernard, H. Russel: Research Methods in Anthropology. Qualitative and Quantitative Approaches. AltaMira Press, 1995

[29] Selmer, Bodil: "Overvejelser om gyldighed og etnografisk metode" Afdeling for Etnografi og Socialantropologi, Aarhus Universitet ,1998 